les sources. Ces «Espaces blancs du carême », ainsi que s'intitulent les deux premières parties disent l'ambivalence de la poésie que restituent les deux typographies. D'un côté le poème est évacué dans sa compromission avec l'histoire, de l'autre, un chant de la terre, des origines, monte du silence: « [...] le déroulement de la matière interrompt sa musique pour interroger l'autre visage du monde ». L'espoir réside dans la présence de l'autre, quand le poète redit sa déchirure devant l'exil et l'horreur. « Je grave au frontispice de ma mémoire la douleur du silence des mots exilés ». L'acte d'écriture est sauvé. Le passé n'est plus négatif, il se recompose en un ferment à partir duquel peut lever la pâte du langage. «Le mot m'invente et m'acclimate aux viols et aux cris ». La poésie offre une seconde naissance et donne un au-delà de la mémoire. Elle crée l'homme par la force de ses mots et de ses images. Quelques poèmes de cette deuxième partie se terminent par « Maintenant». Ils disent cette mémoire qui se prépare à s'élever: « Maintenant, la poésie appelle à d'autres divinités ».

La troisième partie «Vers les hauteurs » tente cette ascension mystique: « Jacob monta sur l'échelle pour accéder au ciel. Les compagnons édifièrent la pierre d'ogive vers le grand constructeur. Et, du livre, le héros chercha son destin. »Par l'écriture, le poète tente une ascencion qui puisse lui permettre de se dépasser. Cette recherche du sommet ne va pas sans un passage vers le fondement intérieur de l'être : "C'est ainsi que le sommeil nous prit dans le recommencement du poème ».

Le poème se clôt sur un distique qui constate l'envolée « vers les hauteurs »: «Il n'y avait que l'espace du poème./ Nous avions quitté la Terre. » L'« espace blanc », la page immaculée que le poète noircit, l'habite, le construit, et l'élève.

Bernard Fournier Noailles (France)

Guy Goffette. Un manteau de fortune. Gallimard, 2001.

A près Partance, Guy Goffette nous offre des poèmes. Mais quelle que soit la forme qu'elle prend, son idée demeure. Celle, essentielle pour un poète moderne, de l'heritage rimbaldien. Le mythe du poète errant, le mythe du départ, fonde une partie de ce livre, renouvelé au creuset de l'expérience propre à Guy Goffette. Partagé entre l'enfance remplie de rêves d'amériques et la tentation du départ vers l'ailleurs innommé, le poète revit ses rêves et ses fuites mal assurées, par la lecture. Il est assez rare qu'un poète prenne Rimbaud lui-même comme « compagnon de silence ". Toute la première partie est en effet un hommage au poète de Charleville (rebaptisée Charlestown, non par anglomanie, mais pour reprendre les termes du poètes du « Bateau ivre » lui-même, et aussi, peut-on penser par goût du blues, à la manière de Jacques Réda (cf Tacatam blues, repris dans la collection poésie de chez Gallimard). Mais, et c'est par là que Guy Goffette fait en quelque sorte travail exceptionnel, il admet aussi Verlaine (On se souvient de son Verlaine d'ardoise et de pluie, 1996, Folio) et la forme fixe. Travail paradoxal pour qui veut chanter la modernité. Mais la liberté ne consiste-t-elle pas à inventer se propres formes? Tout le recueil est ainsi un mélange très savant de formes fixes (parfois avec rimes, alexandrin et sonnet) et d'une langue à l'allure très libre d'une prose coulante, mais en fait tendue par les litanies, les mots à double entente et le suspens des longues phrases sautant par-dessus les vers et les strophes. Au total, des rappels de Rimbaud et de Verlaine, peut-être plus du Verlaine lyrique, et plus du Rimbaud critique, pour un poète des temps modernes qui chante juste d'une voix personnelle et profonde.

Tout le travail de Guy Goffette prend appui sur l'art. Que ce soit la poésie avec ses « 
dilectures » (Rimbaud et Verlaine, bien sûr mais aussi Auden et Henri Thomas), ou la peinture avec une conversation suivie sur neuf poèmes avec Félicien Rops ou encore avec une réflexion poétique à partir d'un tableau de Bruegel, Paysage avec la chute d'Icare. On sait que dans ce tableau, la chute d'Icare est placée en arrière plan d'un paysan et son araire. Icare représente le rêve de l'enfance, il est le prétexte à une réflexion sur le monde des adultes qui se termine par une note pessimiste: «nous ne sommes plus qu'une trace déjà/ dans la nuit, la retombée d'un songe// entre les rails du présent, et qui s'efface ». Cette conclusion sonne dans tout le livre de façon identique. Le poète dit son mal de vivre dans le temps, mais aussi dans la société : « je prie que la terre/ se renverse en un sursaut de honte// et de colère à la face des puissants... » Le rêve, l'idéal, ont encore des forces cachées dans l'âme de l'enfant qu'est toujours un peu le poète. C'est ce qui lui permet de toujours trouver les mots pour la révolte.

Au total voilà un recueil riche de sentiments, de vigueur dans l'écriture, malgré le ton désanchanté de l'homme.

Bernard Fournier

Guillevic. Art poétique, précédé de Paroi, suivi de Le Chant, Préface de Serge Gaubert. Poésie/ Gallimard, 2001.

O uatre ans après sa dispariton on retrouve Guillevic chez Gallimard, et on redécouvre combien sa poésie est limpide, vraie et juste, humaine. L'éditeur lui consacre un quatrième volume dans sa célèbre collection Poésie, mettant ainsi la moitié de l'oeuvre en collection de poche. L'édition ajoute à Art poétique (1989), et à son pendant que constitue Le Chant (1990), le poème Paroi (1970), auquel on ne s'attendait pas. C'est là une heureuse surprise. Elle redonne à Guillevic une image un peu différente de celle à laquelle on s'était habitué. Paroi, s'avance dans des terres apparamment éloignées du breton matérialiste de Terraqué. Et avance dans une forme de poésie qu'on pourrait appeler philosophique.

S'il y a des traces de discours dans ce poème, elles s'élèvent au niveau de la poésie. L'incipit en est révélateur : " Je dois te dire,/ Bien qu'il m'en coûte/ Que tu saches:// Quand je suis seul,/ Je parle. " D'emblee, un dialogue s'instaure sur le ton familier de la confidence. Le poète propose une ouverture plus large quand il se sent enfermé dans ses propres manières de penser : "Il y a donc/ A découvrir. » C'est pourquoi, a contrario le verbe tend parfois à la définition, forme recluse : « Essayer/ D'être la question/Qui s'accepte indemne de réponse. » Le texte tourne autour de la problématique de la question. En l'occurrence, ici, la « paroi ».

Ce thème n'est pas éloigné des «Murs » de Terraqué, ou même des « Rocs », fermés sur euxmêmes, « paroi de roc », comme le définit bien Serge Gaubert dans sa préface. L'auteur pense aussi au «mur [...] les lamentations », et à la paroi «barbelée. Electrifiée». La paroi est une occultation intérieure qu'il s'agit d'éclairer. Guillevic rejette l'idée de Dieu que la «paroi » aurait pu fait naître. Récemment Michel de Maulne (dans un entretien avec Bernard Mazo, in Aujourd'hui poème, $\mathrm{n}^{\circ} 19$, mars 2001), rendait compte des derniers moments de Guillevic « en profondeur, vraiment dans une sorte de méditation profonde d'ordre mystique. » Le poète avoue sa difficulté quand il affronte «ce qui en [lui] est paroi »: "Facile à dire,/ Facile à se promettre.// Mais vivre me parjure. ». Il termine par un infinitif qui dit l'ouverture: « Rêver le temps/ Devenu corps».

\section{LittéRéalité 124}

